\title{
¿Los elementos de la responsabilidad extracontractual del Estado en Colombia son dos o tres?: a propósito de la relación de causalidad*
}

\author{
Is the Extra-Contractual Responsibility of the State in Colombia Comprised of Two or Three Elements? Regarding \\ the Causal Relationship
}

\author{
Hugo André Arenas Mendoza ${ }^{\text {a }}$ \\ Universidad del Rosario, Colombia \\ hugo.arenas@urosario.edu.co \\ ORCID: https://orcid.org/0000-0002-2832-5224
}

DOI: https://doi.org/10.11144/Javeriana.vj69.eree

Recibido: 25 Septiembre 2019

Aceptado: 13 Enero 2020

Publicado: 15 Agosto 2020

\section{Resumen:}

Este artículo de investigación tiene por objetivo demostrar que no existe claridad entre los operadores jurídicos acerca de los elementos de la responsabilidad del Estado en Colombia, puesto que el Consejo de Estado en sus decisiones recientes en ocasiones utiliza dos elementos y en otras tres. La metodología aplicada parte de un análisis histórico de la manera en la que el Consejo de Estado, desde sus primeras decisiones, ha establecido los elementos de la responsabilidad estatal. En un segundo momento, presenta la normatividad actual sobre la materia y, finalmente, se analizan decisiones recientes de cada uno de los magistrados que conforman la Sección Tercera. A partir del análisis, se ha concluido la necesidad de que el Consejo de Estado unifique su posición sobre los elementos necesarios para que se genere la responsabilidad patrimonial y, particularmente, mantenga la constatación de la relación de causalidad como un elemento esencial en sus decisiones. La determinación de los elementos de la responsabilidad por vía jurisprudencial permitirá superar contradicciones teóricas, dificultades prácticas y, sobre todo, evitar sentencias en las que se desconozcan los derechos de las víctimas.

Palabras clave: responsabilidad, Estado, elementos, causalidad, Colombia, víctimas.

\begin{abstract}
:
This research article aims to demonstrate that there is no jurisprudential clarity regarding the elements of State responsibility in Colombia. In recent decisions, the State Council (Consejo de Estado) in some cases applies two elements and in other cases three. The methodology herein applied is based upon a historical analysis of how the State Council has, since its earliest decisions, established the elements of state responsibility. Second, I will present the current law on this subject and, finally, I analyze recent decisions of each of the judges making up the Third Section of the court. From this analysis, it is concluded the need for the State Council to unify its position on the necessary elements to establish property liability and to maintain the causal relationship as essential elements of their decisions. The determination of the elements of responsibility through jurisprudential means will allow the court to overcome theoretical contradictions, practical difficulties, and, above all, avoid decisions in which the rights of victims could be compromised.
\end{abstract}

Keywords: responsibility, State, elements, causal, Colombia, victims.

\section{Introducción}

Uno de los aspectos relevantes en el tema de la responsabilidad extracontractual estatal son los elementos que la configuran, puesto que el cumplimiento de estos requisitos son los que permiten tanto hacer exigibles los derechos de las víctimas frente a los daños cometidos por las acciones u omisiones estatales como prevenir lesiones futuras ${ }^{1}$.

El derecho administrativo colombiano ha tenido un desarrollo particular Sobre este tema, realizado por parte de la jurisprudencia del Consejo de Estado de Colombia que, mediante sus decisiones, ha interpretado que no son tres los elementos de la responsabilidad, sino que son tan sólo el del daño antijurídico y el de

Notas de autor

a Autor de correspondencia. Correo electrónico: hugo.arenas@urosario.edu.co 
la imputación, por lo que se deja de lado el de la causalidad. Con lo que se desconoce la importancia de la exigencia de vínculo de causalidad en la responsabilidad extracontractual patrimonial ${ }^{2}$.

Aunque la corporación ha establecido que para que se genere la responsabilidad estatal es imprescindible que se presenten dos elementos: el daño y la imputación, no existe sentencia de unificación sobre el punto. De este modo, se separa de la responsabilidad tradicional que exige tres elementos que se pueden constatar tanto en el derecho civil como en el público. Considero que deben mantenerse los tres elementos que son el daño ${ }^{3}$, la imputación ${ }^{4}$ y la relación de la causalidad ${ }^{5}$.

Esto se debe al fuerte impulso teórico que fue desarrollado por parte la Subsección C de la Sección Tercera, cuanto tenían como magistrados a Enrique $\mathrm{Gil}^{6}$ y a Jaime Santofimio, quienes defendieron sus tesis en su jurisprudencia, en la que no se debía entender como un elemento aparte la relación de causalidad, sino que bastaba hacer referencia a la imputación. Adicionalmente, tuvieron un impacto mucho mayor al ser los dos doctrinantes más prolíferos, principalmente por sus obras de responsabilidad extracontractual del Estado ${ }^{7}$ y el compendio de derecho administrativo ${ }^{8}$, respectivamente.

Asimismo, la Sentencia de Unificación ${ }^{9}$ de la Sección Tercera del Consejo de Estado con ponencia del magistrado Hernán Andrade del 19 de abril de $2012^{10}$, que unificó solamente sobre títulos de imputación y no sobre los elementos de la responsabilidad, ha contribuido a que se algunos operadores jurídicos hayan considerado incorrectamente que se produjo el paso a dos elementos de la responsabilidad que son el daño antijurídico e imputación.

Esta modificación teórica tiene fuertes implicaciones en la práctica al producir inseguridad jurídica, violaciones al derecho de debido proceso y también puede impactar en las decisiones que sobre el tema se tomen en la jurisdicción contenciosa administrativa. Con base en los argumentos que he vendido esbozando desde hace más de ocho años en mis clases de responsabilidad estatal (en las Universidades del Rosario y de los Andes) y de manera escrita a partir de $2014^{11}$ (actualizadas en $2018^{12}$ ) se expondrá de una forma más detallada en este artículo por qué la jurisprudencia debería retomar la división tripartita con los elementos del daño, imputación y relación de causalidad, con el fin de realizar un aporte novedoso sobre este difícil tema.

En este orden de ideas, para la realización de este artículo fue necesario recurrir a diversas metodologías como la histórica y la dogmática a fin de realizar tanto un estudio doctrinal como un fuerte análisis jurisprudencial de las sentencias de la Corte Constitucional y del Consejo de Estado. El objetivo es poder demostrar la conveniencia de que la jurisdicción especial (o administrativa) acoja uniformemente la tesis propuesta: los elementos esenciales para configurar la responsabilidad estatal en el derecho colombiano deben ser el daño antijurídico, la imputación y la relación de causalidad.

A continuación, se desarrollan los tres argumentos principales para fundamentar la necesidad de que el Máximo Tribunal de lo Contencioso Administrativo colombiano emita una sentencia de unificación ${ }^{13}$ en torno a la existencia de estos tres elementos para configurar la responsabilidad estatal y que se mantenga el estudio del muy relevante componente denominado "relación de causalidad"14.

Antes de comenzar el análisis, se debe indicar que la jurisprudencia seleccionada fue tomada tanto de los Anales como de la Relatoría del Consejo de Estado, dependiendo de la fecha en que fueron resueltas las mismas. Adicionalmente, se debe advertir que entre más antigua fue la jurisprudencia encontrada había menos decisiones debido a la competencia restringida del órgano de cierre de la jurisdicción contenciosa. En cambio, recientemente, resultó más sencillo encontrar referencia a la relación causal, tanto por la ampliación de su competencia como por el número de procesos que se fallaron. Ante estos inconvenientes, fue necesario seguir principalmente los criterios de temporalidad de las decisiones, la novedad de su contenido, la mención textual de la relación causal o sus eximentes y la diversidad de los magistrados ponentes.

Debido a esto, se abordarán los siguientes tres principales argumentos: 1 . El mantenimiento de la división tripartita en la historia de la responsabilidad estatal dentro del Consejo de Estado colombiano; 2. El ordenamiento jurídico colombiano mantiene un esquema de responsabilidad basado en tres elementos; y 
3. Una mirada a la jurisprudencia actual del Consejo de Estado permite afirmar la conservación de los tres requerimientos en gran parte de sus decisiones.

\section{El mantenimiento de la división tripartita en la historia de la jurisprudencia del consejo de estado de Colombia}

En este apartado pretendo demostrar como la jurisprudencia nacional en materia de responsabilidad administrativa ha mantenido históricamente los tres elementos de la responsabilidad estatal.

Recordemos que la jurisdicción ordinaria tuvo conocimiento de tema de responsabilidad estatal desde 1864 hasta 1913 de manera exclusiva y desde 1914 hasta 1964 su jurisdicción fue compartida con el Consejo de Estado ${ }^{15}$. A su vez, el Consejo de Estado tuvo competencias compartidas desde 1914 a 1963 y tuvo conocimiento exclusivo a partir del Decreto 528 de 1964 hasta la fecha.

Con base en lo anterior, y por efectos metodológicos, es conveniente dividir esta parte del texto en: los elementos de la responsabilidad estatal en las sentencias del Consejo de Estado de 1914 a 1963; los elementos de la responsabilidad estatal en las sentencias del Consejo de Estado entre 1964 y1990 y los elementos configuradores de la responsabilidad estatal desde 1991 hasta hoy en las decisiones del Consejo de Estado.

\section{Los elementos de la responsabilidad estatal en las sentencias del Consejo de Estado de 1914 a 1963}

El Consejo de Estado conoció de los casos de responsabilidad estatal desde la Ley 130 de 1914 cuando le atribuyeron funciones jurisprudenciales en el artículo $18^{16}$, antes las decisiones provenían exclusivamente de la jurisdicción ordinaria (Corte Suprema Federal ${ }^{17}$ y Corte Suprema de Justicia ${ }^{18}$ ).

A partir de la fecha, el Alto Tribunal de lo Contencioso Administrativo conoció específicamente de los daños causados por guerra y, con la Ley 30 de 1918 , en su artículo $1^{19}$, se ampliaría a los casos de responsabilidad por operaciones administrativas, mientras que la competencia general la mantendrá la Corte Suprema de Justicia.

Esta situación cambiaría con la expedición de la Ley 167 de 1941 o Código Administrativo que amplió brevemente la competencia de la jurisdicción especial ${ }^{20}$ en virtud del artículo $34^{21}$, y tan sólo con el Decreto 528 de 1964 se le otorgó toda la competencia en materia de responsabilidad estatal al Consejo de Estado.

Una vez hechas las anteriores precisiones, se transcribieron dos apartes de la jurisprudencia del Consejo de Estado para probar que uno de los elementos configuradores de la responsabilidad, en el lapso 1914 a 1963, fue la relación de causalidad y también que existían los eximentes que permitían desvirtuar ese vínculo.

\footnotetext{
También invoca el señor fiscal este argumento exceptivo de que habla el artículo primero de la Ley 95 de 1890: "Se llama fuerza mayor o caso fortuito el imprevisto a que no es posible resistir, como un naufragio, un terremoto, el apresamiento de enemigos, los actos de autoridad ejercidos por un funcionario público, etc.". Y para dotarlo de mayor autoridad se acoge a la interpretación de la Corte Suprema de Justicia, según la cual los hechos expresados en esa norma "no son los únicos que constituyen caso fortuito, pues hay muchos otros, como la razón lo indica y como lo deja entender el etcétera final del artículo”.

Todo esto es verdad, pero acaso en este proceso no tenga el argumento. Porque, como claramente aparece de la disposición, para que haya caso fortuito es preciso que concurran dos elementos, a saber: que sea imprevisto y que, y que la resistencia sea imposible.

$[\ldots]$

Otro aspecto tratado por el señor fiscal en defensa de la Nación, es el de la culpa concurrente y lo plantea así: "Según los Hermanos Henry y León Mazeaud, Lalou y las doctrinas de la Corte Suprema de Justicia, es el error de conducta de quien sufrió actos lesivos de sus derechos patrimoniales, porque ese error conlleva el concepto de culpa, culpa que se enfrenta a la del autor material y directo del acto o hecho o directo del acto o hecho que causó los perjuicios". 


\begin{abstract}
Finalmente, el señor fiscal arguye, en pro de la nación, el hecho culposo de un tercero, y lo explica, de acuerdo con la doctrina de la Corte que acaba de citar, como fenómeno jurídico que ocurre cuando intervienen actividades de un tercero que aparezcan evidentemente vinculadas por una relación de causalidad exclusiva e inmediata con el daño causado, caso en el cual la responsabilidad anexa a la noción de culpa se desplaza del autor del daño hacia el tercero en seguimiento de la causalidad que es uno de los elementos jurídicos esenciales de la responsabilidad ${ }^{22}$.

Relación causal. La sola comprobación de la culpa y el daño tomados aisladamente no son elementos suficientes para estructurar la obligación de reparación, ya que es absolutamente necesaria la relación de causalidad entre falta y daño, o sea, la relación de causa a efecto. El principio de la causalidad tiene suma importancia para la fijación del daño y su alcance. Esa relación de causa a efecto, defendida por los tratadistas como Larombiere y Demolombe, en casos como el presente entre la falta y el daño inicial y entre la falta y el daño final para asegurar así la debida reparación ${ }^{23}$.
\end{abstract}

\title{
Los elementos de la responsabilidad estatal en las sentencias del Consejo de Estado entre 1964 y 1990
}

A partir de 1964, con el Decreto 528, el Consejo de Estado tuvo el conocimiento exclusivo de los casos de responsabilidad estatal ${ }^{24}$, particularmente quedó establecido en su artículo $30^{25}$. Así, el Consejo de Estado tuvo la prevalencia sobre el conocimiento de los casos en los que se demande a las entidades públicas por las controversias que versan sobre responsabilidad nacional y de los establecimientos públicos, es decir, se extiende la responsabilidad a los establecimientos públicos de los diversos niveles territoriales como lo había venido haciendo la jurisprudencia.

En esta época se produjo el primer auge de las teorías causales en la jurisprudencia del Consejo de Estado, al tener que decidir casos de tan diversa naturaleza, y viéndose avocados a estudiar las tesis tanto de la Corte Suprema de Justicia como presentes en el derecho comparado para poder dar solución a las controversias que tuvieron que conocer por sus nuevas facultades.

Eventualmente, la competencia del Consejo de Estado, en materia de responsabilidad estatal, fue confirmada con la expedición del Decreto-ley 01 de 1984, que estableció la acción de reparación directa en su artículo $86^{26}$.

Sobre la existencia de la relación de causalidad como elemento constitutivo de la responsabilidad extracontractual patrimonial de Estado, se citarán cinco apartados que prueban su utilización por el Alto Tribunal Contencioso.

- Si a lo anterior se agrega que, según el reconocimiento hecho por la Oficina de Medicina Legal, al señor Bendeck Olivella y en donde se lee que las lesiones sufridas por el actor fueron causadas por "proyectiles blindados de arma de fuego de largo alcance" y que este tipo de armas es de uso exclusivo del Ejército, el cual, como también se halla demostrado, detuvo la manifestación de la que formaba parte Bendeck y disparó sobre ella. Y si además se tiene en cuenta que al señor Jaime Ortiz quien cayó herido junto a Bendeck le fue extraído un proyectil blindado (camiseta y núcleo) y corresponde a cartucho de fusil, necesariamente se llega a la conclusión de que el tercer presupuesto (relación de causalidad) está probado dentro del expediente. ${ }^{27}$

- Cuando el Estado, en desarrollo de sus funciones incurre en la llamada "falta o falla del servicio", o mejor aún falta o falla de la Administración, trátese de simples actuaciones administrativas, omisiones hechos y operaciones administrativas, se hace responsable de los daños causados al administrado. Esta es la fuente común y frecuente de la responsabilidad estatal y requiere:

a) Una falta o falla del servicio o de la Administración, por omisión, retardo, irregularidad, ineficiencia o ausencia del servicio. La falta o falla de que se trata, no es la personal del agente administrativo, sino la del servicio o anónima de la Administración; 
b) Lo anterior implica que la Administración ha actuado o ha dejado de actuar, por lo que se excluyen los actos del agente, ajenos al servicio, ejecutados como simple ciudadano;

c) Un daño que implica la lesión o perturbación, de un bien protegido por el derecho, bien sea civil, administrativo, etc., con las características generales predicadas en el derecho privado para el daño indemnizable, como de que sea cierto, determinado o determinable, etc.;

d) Una relación de causalidad entre la falta o falla de la Administración y el daño, sin la cual, aún demostrada la falta o falla del servicio, no habrá lugar a la indemnización ${ }^{28}$.

- Por ello, no obstante que la Sala se separa del concepto Fiscal que no parece contemplar la posibilidad de que el Estado responda por el retardo en el cumplimiento de las sentencias judiciales, en el caso concreto no encuentra evidencia la falla del servicio, pues, aparece que, dentro de las prescripciones legales y constitucionales, se hicieron las diligencias y se abrieron los créditos presupuestales para el pago de lo debido.

(...)

Por lo demás el certificado traído a los autos sobre la apropiación de $\$ 20.000 .000$ para pagar deudas por sentencias exigibles por valor de 220.000.000, constituye, en verdad, falla administrativa pero no hay relación de causalidad con un retardo en el cumplimiento del fallo cuestionado en este juicio, pues ya se vio que cuando se expidió presupuesto para el correspondiente ejercicio fiscal aún no se encontraba ejecutoriada dicha sentencia y, por lo mismo, no podría incluirse partida alguna para su cumplimiento a tenor del artículo 210 de la Constitución Política. ${ }^{29}$

- La responsabilidad derivada de los trabajos públicos es objetiva en el derecho colombiano. Por esa razón, causado el daño a un tercero la entidad dueña de la obra deberá resarcirlo, sin poder exonerar alegando la diligencia y el cuidado en la ejecución de la obra. En otros términos, no tendrá el perjudicado que probar la culpa o la falla de la administración, el daño y su relación de causalidad, sino únicamente los dos últimos extremos.

(...)

Para la Sala se produjo, en cierta forma, un despojo de propiedad particular y con éste un perjuicio equivalente a su dueño. Despojo que presenta una relación causal con la ejecución de la obra de propiedad, como se dijo, de la Nación. Y que muestra la conducta irregular del consorcio, el que debía adquirir por su cuenta y riego los materiales necesarios para la obra pública, porque el Fondo, a su turno tenía que reconocérselos. ${ }^{30}$

- La conducta administrativa indicada desconoce el mandato de la citada Ley 23 de 1982 y conforma una clara falla del servicio. La administración no tiene frente a los derechos de los autores ningún privilegio exorbitante y se encuentra frente a ellos en situación similar a la de los particulares. No obstante, puede afirmarse que es la propia administración la que tiene que dar ejemplo en este campo, porque no puede olvidarse que las autoridades están instituidas primordialmente para salvaguardar la vida, honra y bienes de los asociados (art. 16 de la Constitución). Norma esta que constituye uno de los pilares constitucionales de la responsabilidad estatal por hechos u omisiones. Así mismo la Sala acepta la apreciación del a quo en el sentido de que fuera de esa falla del servicio también se demostró el perjuicio y la relación de causalidad entre éste y el hecho causal o falla. ${ }^{31}$

\section{Los elementos configuradores de la responsabilidad estatal desde 1991 hasta hoy en las decisiones del Consejo de Estado}

A los pocos años de la expedición del Código Contencioso Administrativo o Decreto Ley 01 de 1984, se produjo la introducción de la Constitución Política de Colombia de 1991, que elevó a rango constitucional 
la responsabilidad estatal en el artículo 90. Además, se debe recordar que la Ley 1437 de 2011 o CPACA desarrolló el tema de la acción de reparación directa en su artículo $140^{32}$.

Como estos temas se abordarán posteriormente, nos corresponde traer a colación dos sentencias del Consejo de Estado que se produjeron con posterioridad tanto de la entrada de la Constitución Política de 1991 como del Código de Procedimiento Administrativo y de lo Contencioso Administrativo de 2011, para poder ilustrar lo referente a la inclusión de la relación de causalidad durante este periodo.

- 16.11. Valorado en su conjunto el acervo probatorio, para la Sala se encuentra demostrado lo siguiente: i) la existencia de una actividad legítima y lícita de la administración consistente en la aspersión aérea de glifosato llevada a cabo el día 15 de enero de 1999, la cual comporta una fuente de alto riesgo para los bienes patrimoniales y extrapatrimoniales de las personas que no están obligadas a soportarlos; ii) el perjuicio ocasionado al señor Medina, particularmente sobre el cultivo de lulo, fue fruto de la concreción de un riesgo excepcional que se originó por el ejercicio legítimo de una actividad peligrosa; iii) el nexo de causalidad entre la actividad legítima de la administración y los efectos de la lesión ambiental concretada en un daño antijurídico padecido por el demandante e imputable a la entidad de demandada. ${ }^{33}$

- En consecuencia, pese a verificarse el daño alegado, consistente en la muerte de Zenón Fabio Quintero Barona, y la anotada omisión en la prestación del servicio médico por parte del Hospital Departamental Mario Correa Rengifo, no se acreditó, se itera, el nexo de causalidad entre esa conducta irregular y negligente del Estado y la muerte del paciente ${ }^{34}$.

Del anterior apartado se pueden derivar las siguientes ideas: a) durante el lapso de 1914 a 1963 en que el Consejo de Estado tuvo la jurisdicción compartida en materia de responsabilidad estatal se encuentra como elemento esencial la relación de causalidad; b) en el tiempo de jurisdicción exclusiva previo a la Constitución de 1991 se observan también referencias al nexo causal como requisito indispensable; c) a partir de la expedición de la Constitución de 1991 se mantuvo la relación de causalidad como un requerimiento ineludible para la generación de la responsabilidad estatal, tendencia que continúo con posterioridad a la Ley 1437 de 2011; d) resulta clara la existencia histórica en la jurisprudencia del Consejo de Estado de la relación de causalidad como un elemento constitutivo de la responsabilidad extracontractual patrimonial estatal; ye) La relación de causalidad está claramente relacionado con la exoneración de la responsabilidad estatal.

\section{El ordenamiento jurídico colombiano mantiene un esquema de responsabilidad basado en tres elementos}

Se debe empezar por destacar que en el derecho actual colombiano se mantiene un esquema de responsabilidad extracontractual del Estado en el que se requiere la presencia de los tres elementos para que se configure la responsabilidad estatal que son el daño, la imputación y la relación de causalidad.

Para demostrar el anterior postulado, es necesario remitirse al actual bloque de constitucionalidad y a la principal ley vigente sobre la materia, puesto que son estas fuentes las que orientan la actividad de los operadores jurídicos colombianos.

Con base en lo anterior, corresponde, en primer lugar, observar tanto el contenido textual del artículo 90 de la Constitución como las interpretaciones que sobre el tema ha realizado la corte constitucional y, en segundo lugar, es necesario remitirse a la Ley 1437 de 2011 que desarrolla el tema en su artículo 140 sobre la pretensión de reparación directa. Así, este apartado se divide en: tanto la Constitución Política de 1991 como la Corte Constitucional desarrolla los tres requisitos y el Código de Procedimiento y de lo Contencioso Administrativo o Ley 1437 de 2011 mantiene un esquema de responsabilidad basado en tres elementos. 


\section{Tanto la Constitución Política de 1991 como la Corte Constitucional desarrolla los tres requisitos}

La norma base dentro del Estado Social y Democrático de Derecho colombiano sobre la que se construye el régimen de responsabilidad extracontractual del Estado es el artículo 90 de la Constitución Política, que elevó a rango constitucional el principio de responsabilidad ${ }^{35}$, lo que permitió la ampliación del espectro de la responsabilidad estatal ${ }^{36}$. De este modo, como lo explica Enrique Gil: “[...] no es más que la mera consecuencia de la filosofía que traza la Constitución Política, circunscrita por principios y valores superiores del ordenamiento jurídico, como la dignidad, la igualdad, la libertad, la justicia, el pluralismo político, la solidaridad, la equidad, el Estado social Derecho, etc." ${ }^{37}$.

El artículo 90 de la Constitución Política de 1991 es la norma fundamental del ordenamiento jurídico para estudiar el régimen de responsabilidad del Estado en Colombia al establecer:

Art. 90. El Estado responderá patrimonialmente por los daños antijurídicos que le sean imputables, causados por la acción o la omisión de las autoridades públicas.

En el evento de ser condenado el Estado a la reparación patrimonial de uno de tales daños, que haya sido consecuencia de la conducta dolosa o gravemente culposa de un agente suyo, aquel deberá repetir contra este.

Es evidente que el artículo 90 de la Constitución está compuesto por dos párrafos. El primero, establece los lineamientos generales de responsabilidad patrimonial de la administración pública, mientras que el segundo establece la acción de repetición ${ }^{38}$ que tienen las entidades estatales contra sus funcionarios públicos en los casos en los que la responsabilidad sea consecuencia de su comportamiento culposo o doloso ${ }^{39}$.

Con base en lo anterior, es necesario centrarse en el primer párrafo del que se desprende la presencia de varios elementos de la responsabilidad, que hace referencia a los "daños antijurídicos", "que le sean imputables" y “causados por la acción u omisión”, es decir, a los tres elementos tradicionales de: 1 . Daño (antijurídico ${ }^{40}$ ), 2. Imputación y 3. Relación de causalidad.

Por su parte, aunque en ocasiones la Corte Constitucional ha defendido la existencia de dos elementos como en la Sentencia C-333 de $1996^{41}$, dicha antigua providencia puede llevar a varias interpretaciones en materia de responsabilidad contractual.

Es indudable que en otra jurisprudencia posterior se ha hecho referencia a los tres elementos, por ejemplo: en la sentencia C-892 de $2001^{42}$; en la providencia C-644 de $2011^{43}$; en el proceso C-286 de $2017^{44}$ y en la reciente decisión T-066 de $2019^{45}$.

\section{El Código de Procedimiento y de lo Contencioso Administrativo o Ley 1437 de 2011 mantiene un esquema de responsabilidad basado en tres elementos}

La principal norma de rango legal que desarrolla el tema de la responsabilidad estatal en Colombia a partir de los postulados del artículo 90 de la Constitución Política es el Código de Procedimiento y de lo Contencioso Administrativo CPACA o Ley 1437 de 2011, puesto que en su artículo 140 incorpora la pretensión de reparación directa en los siguientes términos:

Art. 140. Reparación directa. En los términos del artículo 90 de la Constitución Política, la persona interesada podrá demandar directamente la reparación del daño antijurídico producido por la acción u omisión de los agentes del Estado.

De conformidad con el inciso anterior, el Estado responderá, entre otras, cuando la causa del daño sea un hecho, una omisión, una operación administrativa o la ocupación temporal o permanente de inmueble por causa de trabajos públicos o por cualquiera otra causa imputable a una entidad pública o a un particular que haya obrado siguiendo una expresa instrucción de la misma. 
Las entidades públicas deberán promover la misma pretensión cuando resulten perjudicadas por la actuación de un particular o de otra entidad pública.

En todos los casos en los que en la causación del daño estén involucrados particulares y entidades públicas, en la sentencia se determinará la proporción por la cual debe responder cada una de ellas, teniendo en cuenta la influencia causal del hecho o la omisión en la ocurrencia del daño.

Como se puede observar, la acción de reparación directa del artículo $140^{46}$ de la ley 1437 de 2011 está dividida en cuatro párrafos. El primer inciso recoge el régimen general de la responsabilidad general contenido en el artículo 90 de la norma fundamental; en el segundo, recoge una serie de hipótesis taxativas por las cuales el Estado debe responder; el tercero establece la posibilidad que tienen las entidades públicas de ejercer la acción de reparación en contra de otra persona jurídica de derecho público; y el cuarto, explica que cuando la responsabilidad sea concurrente, se debe determinar el grado de participación de cada agente en la materialización del daño.

Como se puede observar, el artículo 140 reproduce los tres elementos tradicionales de la responsabilidad estatal que son el daño, la imputación y la relación de causalidad, los cuales son mencionados recurrentemente por el legislador a través del mencionado artículo.

De la normatividad estudiada se derivan las siguientes conclusiones:

1. La Constitución de Colombia hace relación a los elementos del daño, la imputación y la relación de causalidad.

2. La Corte Constitucional en sus decisiones ha mantenido la existencia de los tres elementos.

3. Curiosamente en sus providencias el Máximo Tribunal Administrativo, en ocasiones, hace referencia a los tres elementos basado en sentencias del Consejo de Estado.

4. El artículo 140 del Código de Procedimiento Administrativo y de lo Contencioso Administrativo o Ley 1437 de 2011 mantiene la división tripartita de los requisitos para la responsabilidad estatal.

5. Otra interpretación del artículo 140 del CPACA que pretendiera estructurar la responsabilidad estatal con base en tan sólo dos elementos, proveniente de las ramas ejecutiva, del legislativa o judicial sería abiertamente contraria a la intención del constituyente.

\section{La jurisprudencia del consejo de estado demuestra la conservación de los tres elementos en sus decisiones recientes}

Con el propósito de probar que el Consejo de Estado mantiene su referencia a los tres elementos se han seleccionado extractos de recientes decisiones de pretensiones de reparación directa de esta corporación, provenientes de diferentes magistrados de la Sección Tercera, para que el lector pueda constatar directamente que el elemento no ha sido suprimido de las decisiones. Al contrario, son comunes los apartados considerativos que se refieren a la relación o nexo de causalidad, presentándolo como un elemento necesario (o, por lo menos, es mencionado).

Con el fin de detectar particularidades en la jurisprudencia de la Sección Tercera se abordarán cada una de las subsecciones independientemente. Por tanto, se realizó esta clasificación: la relación de causalidad en las recientes decisiones de la Subsección A del Consejo de Estado; la relación de causalidad en la reciente jurisprudencia de la Subsección B del Consejo de Estado y la relación de causalidad en la Subsección C del Consejo de Estado. 


\section{La relación de causalidad en las recientes decisiones de la Subsección A del Consejo de Estado}

La Subsección A de la Sección Tercera está compuesta por tres magistrados, en los últimos tres magistrados han sido: Martha Velázquez; Adriana Marín y Carlos Zambrano.

\section{Martha Velázquez}

El 16 de mayo de 2019 se decidió sobre una acción en contra de la Policía Nacional por la muerte de un señor que salió del trabajo para encontrarse con un agente policial, y no regresó a su casa; su cuerpo sin vida apareció al día siguiente. En este caso se absolvió a la entidad demandada explicando que no se acreditó la relación de causalidad, concretamente señaló:

Las falencias probatorias puestas de presente llevan a la Sala a la conclusión de que la parte actora no demostró que el homicidio del joven Edilson de Jesús Morales Arenas fuere imputable a la Policía Nacional, de tal suerte que la falta de acreditación de la relación de causalidad supone la ausencia de uno de los elementos de la responsabilidad del Estado, bajo la aplicación de un régimen subjetivo de responsabilidad y ello deviene en el fracaso de las pretensiones. ${ }^{47}$

\section{Adriana Marin}

Bajo sus consideraciones, el 8 de mayo de 2019 se exoneró a la Nación, Ministerio de Defensa y al Ejército Nacional que fueron las entidades demandadas por la detención de un bus de pasajeros sobre una vía nacional y el posterior asesinato de las personas que se trasportaban en el automotor por parte de las FARC. En este caso, se analizó la responsabilidad de las Fuerzas Estatales por omisión, la Alta Corporación terminó por exonerarlas por falta de demostración de la causalidad, explicando:

En efecto, en la responsabilidad del Estado por omisión, se ha considerado que para la prosperidad de la demanda es necesario que se encuentren acreditados los siguientes requisitos: i) la existencia de una obligación legal o reglamentaria a cargo de la entidad demandada de realizar la acción con la cual se habrían evitado los perjuicios; ii) la omisión de poner en funcionamiento los recursos de que se dispone para el adecuado cumplimiento del deber legal, atendidas las circunstancias particulares del caso; iii) un daño antijurídico, y iv) la relación causal entre la omisión y el daño (...). ${ }^{48}$

\section{Carlos Zambrano}

Con la ponencia de este magistrado del 17 de agosto de 2017 que examina una demanda de responsabilidad médica por omisión al no practicar un examen médico, se decidió exonerar por falta de acreditación del nexo causal a la entidad, aduciendo:

De conformidad con lo dicho hasta aquí, lo que se evidencia es que la demandada omitió practicar la laparoscopia diagnóstica, intervención que se debe realizar cuando se presentan las condiciones en las que se encontraba el señor Quintero; sin embargo, dicha omisión no es suficiente para que se declare la responsabilidad patrimonial del establecimiento clínico demandando por la muerte de Zenón Fabio Quintero Barona, en la medida en que no obra elemento alguno a través del cual se logre evidenciar, de manera fehaciente y concluyente, el nexo de causalidad entre ella (la omisión) y el daño alegado, pues no es posible afirmar categóricamente que, de haberse realizado la laparoscopia diagnóstica, se hayan detectado las perforaciones, ni mucho menos que, de haberse realizado el tratamiento médico correspondiente, el paciente haya preservado su vida. ${ }^{49}$ 


\section{La relación de causalidad en la reciente jurisprudencia de la Subsección B del Consejo de Estado}

Así mismo, la segunda Subsección identificada con el literal B de la Sección Tercera del Consejo de Estado, ha estado conformado en los últimos años por Martín Bermúdez, Alberto Montaña y Ramiro Pazos.

\section{Martín Bermúdez}

Resolvió una demanda de responsabilidad estatal por privación injusta de la libertad de una persona que provocó su detención por su propio comportamiento, al explicar que la culpa grave de la víctima puede romper la causalidad y exonerar al Estado. Sin embargo, esta situación no se presentó por lo que se condenó a la entidad, afirmando:

21.6.- Debe estudiarse a cuál entidad debe imputársele el daño y cuando se trate de varias, todas deben ser condenadas de manera solidaria.

21.7.- Por último, debe establecerse si existió dolo o culpa grave de la víctima, pero advirtiendo que este elemento ha de estudiarse como una circunstancia apropiada para romper la relación de causalidad y es sobre este aspecto de la responsabilidad que debe versar su análisis; con lo cual es claro que solo si se demuestra que - en el curso del proceso - una conducta de la víctima fue la que determinó su detención, puede darse por probada esta causal de exoneración de responsabilidad. ${ }^{50}$

\section{Alberto Montaña}

El magistrado no condena a un hospital en un caso de responsabilidad médica por deficiente prestación del servicio de salud debido a que los demandantes no pudieron demostrar el nexo de causalidad entre la prestación del servicio militar que realizaba el paciente y el servicio de salud recibido, exponiendo:

Concluye la Sala, luego del análisis de las pruebas que obran en el expediente que, la parte demandante no acreditó el nexo de causalidad, entre la actuación u omisión de la entidad demandada y, el daño sufrido por el señor Quintero Celis. Lo anterior, toda vez que, si bien se imputó a la "prestación del servicio militar" y, a la deficiente prestación del servicio de salud, dichas circunstancias no fueron demostradas, tal y como se explicó y, en esa medida, resulta evidente, la ausencia de nexo causal. ${ }^{51}$

\section{Ramiro Pazos}

En sentencia del 14 de junio de 2018 decidió exonerar a la entidad demandada por la enfermedad de un soldado conscripto, sosteniendo que no hubo relación de causalidad entre la vinculación al servicio militar y la enfermedad mental que desarrolló el soldado, argumentando:

Lo anterior significa que habrá lugar a declarar la responsabilidad del Ejército Nacional en aquellos casos en que la patología es adquirida con anterioridad a la vinculación a la conscripción, pero su manifestación o detonación tiene relación de causalidad con el servicio militar.

No obstante lo anterior, se observa que el aquí demandante permaneció a disposición de la entidad demandada, mientras se llevaron a cabo los trámites descritos por la ley para ser seleccionado a prestar el servicio militar, sin haberse probado que durante el poco lapso de tiempo haya sido sometido a una situación de máximo peligro o riesgo que desencadenara una crisis de la afectación mental. ${ }^{52}$ 


\title{
La relación de causalidad en la Subsección C del Consejo de Estado
}

La Subsección C de la Sección Tercera del Consejo de Estado está compuesta por los siguientes tres magistrados: Nicolás Yepes, Jaime Rodríguez y Guillermo Sánchez.

\section{Nicolas Yepes}

Al decidir sobre una sentencia de responsabilidad extracontractual médica, concretamente en el caso de un paciente que muere mientras lo trasportaban en una ambulancia a un hospital, condena a la entidad por culpa al reconocer la existencia del nexo causal. Textualmente precisa:

\begin{abstract}
Ahora bien, en el entendido que en el caso en concreto nos ubicamos en la esfera de la falla probada en el servicio, ya que el sub examine no encuadra en ninguno de los eventos de responsabilidad objetiva reconocidos por la jurisprudencia en los eventos de responsabilidad médica, para que se le pueda imputar responsabilidad a las demandadas por la muerte del señor Salomón Ortega Quinayás, los actores, no sólo deben demostrar la existencia del daño, sino también la falla en la que incurrió el personal médico de dichas entidades en la prestación del servicio así como el nexo de causalidad entre uno y otro. $^{53}$
\end{abstract}

\section{Jaime Rodríguez}

Los hechos objeto de análisis ocurren a partir de la muerte de un soldado que es atropellado por un automóvil en una vía principal que debía patrullar. El magistrado concluye que no existe la responsabilidad estatal por el accidente, puesto que este se debió a la conducta imprudente de la víctima. Sobre el nexo causal opinó:

Por lo tanto, no toda conducta asumida por la víctima constituye un factor que rompa el nexo de causalidad entre el hecho y el daño, toda vez que, para que la culpa de la víctima releve de responsabilidad a la administración, debe acreditarse una relación de causalidad entre ella y el daño. Si el hecho del afectado fue la causa única, exclusiva o determinante del daño, la exoneración es total; por el contrario, si tal hecho no tuvo incidencia en la producción de aquél, debe declararse la responsabilidad estatal. ${ }^{54}$

\section{Guillermo Sánchez}

El 19 de septiembre de 2017, frente a un caso de responsabilidad de un soldado por daños causados debido a un accidente producido por la utilización de armas de dotación oficial, condena al uniformado que efectuó el disparo que impactó a su compañero por culpa grave, manifestando:

14. En el ámbito de la responsabilidad administrativa, el uso de armas de fuego ha sido tradicionalmente considerado una actividad peligrosa y, por ello se suele analizar desde la perspectiva de un régimen objetivo de responsabilidad (...).

De ahí que, bastará probar la realización del riesgo creado y la relación de causalidad entre éste y el daño para imputar responsabilidad y la Administración solo se exonerará si se acredita una causa extraña, esto es, fuerza mayor o el hecho exclusivo de un tercero o de la víctima (......$^{55}$

De los anteriores apartados jurisprudenciales se pueden sacar varias conclusiones en cuanto al tema del nexo o relación causal:

1. Los nueve magistrados actuales hacen referencia a la relación de causalidad como elemento esencial.

2. La exoneración de responsabilidad se puede dar por el rompimiento del nexo causal

3. La causalidad se debe demostrar tanto en los casos de acción como los de omisión.

4. En ocasiones se aborda como elemento crucial y en otras como complemento de la imputación. 
5. Así se hable de la imputación como elemento de la responsabilidad estatal, esta se demuestra por medio de una teoría causal que es la teoría de la causalidad adecuada, lo que demuestra que no hace un juicio de imputación sino de causalidad.

\section{Conclusiones}

1. La historia de la responsabilidad estatal en la jurisprudencial del Consejo de Estado de Colombia en todas sus etapas históricas (1914-1963, 1964-1990 y 1991-2019) ha coincidido en que la relación de causalidad es tanto un elemento esencial para su configuración como un factor clave para la exoneración estatal.

2. Para el Consejo de Estado, la existencia del nexo de causalidad se debe demostrar tanto en los casos de responsabilidad por acción u omisión como en los casos de responsabilidad objetiva y subjetiva.

3. La Constitución de Colombia relaciona los elementos del daño, la imputación y la relación de causalidad, este último lineamiento ha sido recogido tanto en la jurisprudencia de la Corte Constitucional como en el artículo 140 del CPACA. Cualquier otra interpretación que pretendiera estructurar la responsabilidad estatal con base en tan sólo dos elementos, proveniente de las ramas ejecutiva, del legislativa o judicial, sería abiertamente contraria a la intención del constituyente.

4. En la actualidad los nueve magistrados actuales hacen referencia a la relación de causalidad como elemento esencial, explicando que la exoneración de responsabilidad se puede dar por el rompimiento del nexo causal. Aunque en ocasiones se aborda como elemento crucial y en otras como complemento de la imputación.

5. Así se hable de la imputación como elemento de la responsabilidad estatal en la jurisprudencia del Consejo de Estado, esta se demuestra por medio de una teoría causal que es la teoría de la causalidad adecuada, lo que prueba que los juristas no hacen un juicio de imputación sino de causalidad.

6. En las mismas decisiones jurisprudenciales del Consejo de Estado hay diversas posiciones entre los magistrados, quienes aplican las teorías de forma contradictoria y, en ocasiones, pese a que dicen realizar un juicio de imputación hacen referencias al nexo causal o a las causales de su rompimiento o de debilitamiento.

7. No existe claridad en los elementos que generan la responsabilidad del Estado en la jurisprudencia del Consejo de Estado, lo que acarrea dificultades prácticas cuando los operadores jurídicos deben someterse a unas tesis muy diferentes a las que estudiaron. Esta confusión se refleja en las demandas y se puede manifestar en violaciones a los derechos de las víctimas.

8. En síntesis, es necesario que el Consejo de Estado por medio de una Sentencia de Unificación presente su posición en materia de los elementos constitutivos de la responsabilidad patrimonial extracontractual del Estado en donde especifique si son dos o tres y si se mantiene la relación de causalidad en este esquema.

\section{Referencias}

Consejo de Estado, 28 de abril de 1967, C. P. Carlos Portocarrero.

Consejo de Estado, 29 de julio de 1947, C. P. Gustavo Valbuena.

Consejo de Estado, 30 de septiembre de 1960, C. P. Francisco Gómez.

Consejo de Estado. Exp. 3646, M. P. Jorge Valencia Arango; 9 de agosto de 1984.

Consejo de Estado. Exp. 5084, M. P. Carlos Betancur Jaramillo; 5 de julio de 1988. 
Consejo de Estado. Exp. 5284, M.P. Carlos Betancur Jaramillo; 31 de enero de 1989.

Consejo de Estado, Sección Tercera, Exp. 29028, M.P. Ramiro Pazos Guerrero; 20 de febrero de 2014.

Consejo de Estado, Sección Tercera, Sala Plena, Exp. 21515, M. P. Hernán Andrade Rincón; 19 de abril de 2012.

Consejo de Estado, Sección Tercera, Subsección A, Exp. 36898, M. P. Carlos Zambrano; 17 de agosto de 2017.

Consejo de Estado, Sección Tercera, Subsección A, Exp. 43332, M. P. Adriana Marín; 8 de mayo de 2019.

Consejo de Estado, Sección Tercera, Subsección A, Exp. 48964, M. P. Martha Velásquez; 16 de mayo de 2019.

Consejo de Estado, Sección Tercera, Subsección B, Exp. 37646, M. P. Ramiro Pazos; 14 de junio de 2018.

Consejo de Estado, Sección Tercera, Subsección B, Exp. 39867, M. P. Martín Bermúdez; 2 de agosto de 2019.

Consejo de Estado, Sección Tercera, Subsección B, Exp. 44900, M. P. Alberto Montaña;15 de julio de 2019.

Consejo de Estado, Sección Tercera, Subsección C, Exp. 43506, M. P. Nicolás Yepes Corrales; 31 de mayo de 2019.

Consejo de Estado, Sección Tercera, Subsección C, Exp. 44745, M. P. Jaime Rodríguez; 29 de abril de 2019.

Consejo de Estado, Sección Tercera, Subsección C, Exp. 51198, M. P. Guillermo Sánchez; 19 de diciembre de 2017.

Consejo de Estado, Sentencia de 17 de agosto de 2017, Exp. 56347, C. P. Carlos Zambrano.

Constitución Política de Colombia [Const]. 7 de julio de 1991 (Colombia).

Corte Constitucional de Colombia. Sentencia C-286 de 2017 (M. P. Gloria Ortíz; 3 de mayo de 2017).

Corte Constitucional de Colombia. Sentencia C-333 de 1996 (M. P. Alejandro Martínez; 1 de agosto de 1996).

Corte Constitucional de Colombia. Sentencia C-644 de 2011 (M. P. Jorge Palacio; 31 de agosto de 2011).

Corte Constitucional de Colombia. Sentencia C-892 de 2001 (M. P. Rodrigo Escobar; 22 de agosto de 2001).

Corte Constitucional de Colombia. Sentencia T-066 de 2019 (M. P. Alejandro Linares; 19 de febrero de 2019).

Decreto 01 de 1984 [con fuerza de ley]. Por el cual se reforma el Código Contencioso Administrativo. 2 de enero de 1984. D. O. 36439.

Diego Younes Moreno, Curso de Derecho Administrativo (10.. ed., Temis, 2016).

Enrique Gil Botero, Responsabilidad extracontractual del Estado (7.. ed., Temis, 2017).

Enrique Gil Botero, Responsabilidad extracontractual del Estado (Editorial Temis, 2013).

Enrique José Arboleda Perdomo, Comentarios al Nuevo Código de Procedimiento Administrativo y de lo Contencioso Administrativo (Legis, 2011).

Gustavo Quintero Navas, La construcción de la responsabilidad del Estado en Colombia, en Manual de Derecho Administrativo (Universidad de los Andes, 2009).

Gustavo Quintero Navas, La responsabilidad del Estado en la Constitución de 1991: ¿Hacia el fin del fallo blanco?, en Corte Constitucional 10 años. Balance y perspectivas (Universidad del Rosario, 2003).

Hugo Andrés Arenas Mendoza, ¿Estado responsable o irresponsable? La responsabilidad patrimonial del Estado colombiano, luego de la Guerra Civil de 1876-1877 (Universidad del Rosario, 2009).

Hugo Andrés Arenas Mendoza, El régimen de responsabilidad subjetiva (2.. ed., Legis, 2018).

Hugo Andrés Arenas Mendoza, Un siglo de Jurisprudencia del Consejo de Estado en materia de responsabilidad extracontractual (1914-2014) (Ibáñez, 2015).

Jaime Orlando Santofimio Gamboa, Compendio de Derecho Administrativo (Universidad Externado de Colombia, 2017).

Jaime Orlando Santofimio Gamboa, Tratado de derecho administrativo (Universidad Externado de Colombia, 2003). Jaime Vidal Perdomo, Derecho Administrativo (Legis, 2009).

Juan Carlos Henao Pérez, Presentación general de la responsabilidad extracontractual del Estado en Colombia, en Segundas Jornadas colombo-venezolanas (Editorial Universidad Externado de Colombia, 1996).

Juan Carlos Henao Pérez, Reflexiones sobre el futuro de la responsabilidad extracontractual del Estado en Colombia, en Congreso internacional de Derecho Público, Filosofía y Sociología Jurídicas: perspectivas para el próximo milenio (Universidad Externado de Colombia, Consejo Superior de la Judicatura, 1996). 
Juan Pablo Sarmiento Erazo, El recurso extraordinario de unificación jurisprudencial, 60 Vniversitas, n. ${ }^{\circ}$ 123, 247-282 (2011). https://revistas.javeriana.edu.co/index.php/vnijuri/article/view/14317

Ley 130 de 1914. Sobre la jurisdicción de lo contencioso-administrativo. 13 de diciembre de 1914. D. O. 15123.

Ley 1437 de 2011. Por la cual se expide el Código de Procedimiento Administrativo y de lo Contencioso Administrativo. 18 de enero de 2011. D. O. 47956.

Ley 167 de 1941. Sobre organización de la jurisdicción Contencioso-administrativa. 24 de diciembre de 1941. D. O. 24853.

Ley 30 de 1918. Por la cual se abre un crédito adicional al Presupuesto de gastos de la vigencia en curso. 15 de octubre de 1918. D. O. 16518.

Libardo Rodríguez, Derecho Administrativo. General y colombiano (Temis, 2015).

Luis Medina Alcoz, La responsabilidad patrimonial de las administraciones públicas (II). Elementos. Factores de exoneración, en Lecciones y materiales para el estudio del derecho administrativo (vol. 4., Iustel, 2009).

Luis Medina Alcoz, La teoría de la pérdida de la oportunidad. Estudio doctrinal y jurisprudencial de derecho de daños público y privado (2007).

Natalia Bernal-Cano, Homenaje al magistrado doctor Enrique Gil-Botero por su legado internacional al derecho de la responsabilidad, 64 Vniversitas, n. ${ }^{\circ}$ 130, 347-364 (2015). http://dx.doi.org/10.11144/Javeriana.vj130.hmde

Ramiro Saavedra Becerra, La responsabilidad patrimonial de la Administración Pública (Ibáñez, 2003).

Sergio Rojas-Quiñones \& Juan Diego Mojica-Restrepo, De la causalidad adecuada a la imputación objetiva en la responsabilidad civil colombiana, 63 Vniversitas, n. ${ }^{\circ}$ 129, 187-235 (2014). https://doi.org/10.11144/Javeriana. VJ129.caio

\section{Notas}

* Artículo de investigación. El artículo es de un integrante del Grupo de Derecho Público de la Universidad del Rosario, adscrito a Colciencias en la Categoría A1. El autor quedó en la última categorización como profesor Asociado en Colciencias.

1 "El derecho de la responsabilidad extracontractual del Estado hoy va más allá de la simple reparación de perjuicios estimados en un caso concreto y se convierte en un instrumento con efectos generales para prevenir los daños indemnizables y restaurar los derechos fundamentales vulnerados por el Estado en circunstancias semejantes". Natalia Bernal-Cano, Homenaje al magistrado doctor Enrique Gil-Botero por su legado internacional al derecho de la responsabilidad, 64 Vniversitas, n. $^{\circ}$ 130, 349-350 (2015).

2 "Pues bien, todo ello se hace patente en la exigencia del vínculo de causalidad. La mejor expresión de que solo somos responsables por los resultados que causemos es la causalidad que, en ese orden de ideas, se erige como la versión jurídica del principio moral de la agencia, en virtud del cual, como somos dueños de nuestras propias acciones, somos también dueños de sus resultados. Allí estriba la importancia de la causalidad”. Sergio Rojas-Quiñones \& Juan Diego MojicaRestrepo, De la causalidad adecuada a la imputación objetiva en la responsabilidad civil colombiana, 63 Vniversitas, n. ${ }^{\circ} 129,191$ (2014).

3 "Daño o lesión es la pérdida o menoscabo de un bien de los que integran el patrimonio de la persona, utilizando la palabra patrimonio en un sentido amplio, que es comprensivo tanto del patrimonio personal (formado por los bienes inmateriales de la persona, extracommercium) como el patrimonio pecuniario o económico (compuesto por los bienes materiales de la persona, intra commercium". Luis Medina Alcoz, La responsabilidad patrimonial de las administraciones públicas (II). Elementos. Factores de exoneración, en Lecciones y materiales para el estudio del derecho administrativo, 69 (vol. 4., Iustel, 2009).

4 "Para que una persona pública pueda ser considerada responsable de algo, debe haberse producido, ante todo, una actuación que le sea imputable, es decir, una conducta de la cual esa persona pública haya sido autora”. Libardo Rodríguez, Derecho Administrativo. General y colombiano, 527 (Temis, 2015).

5 "Un elemento fundamental de la responsabilidad civil está constituido por la relación, nexo, unión, vínculo, conexión, enlace, ligazón o lazo etiológico, causal o de causalidad entre la conducta del sujeto agente y la lesión del sujeto paciente; requisito al que se alude cuando se dice que un sujeto causa, origina, produce, ocasiona, provoca, genera, propicia o gesta un perjuicio; o que el daño es efecto, rastra secuencia, consecuencia, producto, resultado o derivación de la conducta de otro". Luis Medina Alcoz, La teoría de la pérdida de la oportunidad. Estudio doctrinal y jurisprudencial de derecho de daños público y privado, 243 (2007).

6 "El doctor Gil Botero, reconocido erudito y defensor de la reparación integral del daño causado a la persona y a sus bienes patrimoniales, ha dejado en el viejo continente uno de sus más grandes legados. Su obra tiene el mérito 
de atravesar los límites de la percepción clásica de la teoría general de la responsabilidad del Estado, gracias a sus estudios casuísticos fundamentados a profundidad con rigurosos análisis de la jurisprudencia administrativa nacional y de diferentes ordenamientos jurídicos desde una amplia perspectiva comparativa”. Natalia Bernal-Cano, op. cit., 348.

7 "Porque a términos del artículo 90 de la Constitución Política vigente es más adecuado que el juez aborde, en primer lugar, el examen del daño antijurídico, para en un momento posterior explorar la imputación del mismo al Estado o a una persona jurídica de derecho público". Enrique Gil Botero, Responsabilidad extracontractual del Estado, 38 (7.a ed., Temis, 2017).

8 "Luego en su construcción inicial, el régimen de responsabilidad considera tres elementos básicos: a. El daño antijurídico; b. El juicio de imputación, y c. La reparación integral”. Jaime Orlando Santofimio Gamboa, Compendio de Derecho Administrativo, 743 (Universidad Externado de Colombia, 2017).

9 "La unificación de jurisprudencia se convierte en un importante instrumento, cuya fuerza vinculante ha sido resaltada por el artículo 271 que señala incluso el poder preferente, por decirlo de alguna manera, en que el Consejo de Estado asuma asuntos pendientes de fallo, de oficio, a solicitud de parte o a petición del Ministerio Público". Juan Pablo Sarmiento Erazo, El recurso extraordinario de unificación jurisprudencial, 60 Vniversitas, n. ${ }^{\circ}$ 123, 275 (2011).

10 "En lo que refiere al derecho de daños, como se dijo previamente, se observa que el modelo de responsabilidad establecido en la Constitución de 1991 no privilegió ningún régimen en particular, sino que dejó en manos del juez la labor de definir, frente a cada caso en concreto, la construcción de una motivación que consulte razones, tanto fácticas como jurídicas que den sustento a la decisión que habrá de adoptar. Por ello, la jurisdicción contenciosa ha dado cabida a la adopción de diversos 'títulos de imputación' como una manera práctica de justificar y encuadrar la solución de los casos puesto a su consideración, desde una perspectiva constitucional y legal, sin que ello signifique que pueda entenderse que exista un mandato constitucional que imponga al juez la obligación de utilizar frente a determinadas situaciones fácticas un determinado y exclusivo título de imputación”. Consejo de Estado, Sección Tercera, Sala Plena, Exp. 21515, M. P. Hernán Andrade Rincón; 19 de abril de 2012.

11 En este libro expongo los siguientes cuatro: 1. El sostenimiento de los tres elementos es más acorde con la historia del derecho colombiano; 2. En materia de derecho civil se mantiene la división tripartita; 3. La visión desde la perspectiva del derecho comparado y 4. Consideraciones prácticas. Hugo Andrés Arenas Mendoza, Un siglo de Jurisprudencia del Consejo de Estado en materia de responsabilidad extracontractual (1914-2014), 189-191 (Ibáñez, 2015).

12 En los años posteriores se ampliaron los argumentos a estos seis: 1. El sostenimiento de los tres elementos es más acorde con la historia del derecho colombiano; 2. La Corte Constitucional defiende la existencia de tres elementos; 3. Al estudiar parte de la jurisprudencia del Consejo de Estado que sigue la clasificación de imputación fáctica e imputación jurídica, que al parecer toma del Derecho italiano o del español; 4. En el derecho civil se mantiene la división tripartita; 5. La visión desde la perspectiva del derecho comparado y 6. Consideraciones prácticas. Hugo Andrés Arenas Mendoza, El régimen de responsabilidad subjetiva, 221-223 (2.. ed., Legis, 2018).

13 "El reconocimiento por el trabajo desarrollado por el Consejo de Estado se hace evidente con la categorización de dichos fallos como sentencias unificadoras entendiendo, en virtud de la causal de unificación, que las mencionadas sentencias sean 'consistentes' debido a que la sentencia de unificación tiene la característica de lograr la unidad de la interpretación del derecho". Juan Pablo Sarmiento Erazo, op. cit., 275.

14 "Así mismo, la comprobación de la existencia de un nexo de causal entre la actuación de un sujeto y un menoscabo injustificado en los derechos de una persona permite al juzgador, a la hora de un juicio de responsabilidad civil, imponer la condena única y exclusivamente al causante del daño y obligarlo a resarcir solamente los perjuicios que ocasionó con su conducta”. Sergio Rojas-Quiñones \& Juan Diego Mojica-Restrepo, op. cit., 198.

15 "De aquí que calificamos este período como mixto; la razón de esta continuidad con dos jurisdicciones prácticamente conociendo de litigios de la administración pública nos demuestra el arraigo del sistema judicialista colombiano y la imposibilidad de una ruptura total frente a la importación francesa”. Jaime Orlando Santofimio Gamboa, Tratado de derecho administrativo, 327-328 (Universidad Externado de Colombia, 2003).

16 "Art. 18. El Tribunal Supremo conoce privativamente en una sola instancia de los asuntos siguientes: a)\# De los negocios sobre suministros, empréstitos y expropiaciones en tiempo de guerra. [...]”. Ley 130 de 1914. Sobre la jurisdicción de lo contencioso-administrativo. 13 de diciembre de 1914. D. O. 15123.

17 Hugo Andrés Arenas Mendoza, ¿Estado responsable o irresponsable? La responsabilidad patrimonial del Estado colombiano, luego de la Guerra Civil de 1876-1877, 114-131 (Universidad del Rosario, 2009).

18 "La jurisprudencia de la Corte Suprema de Justicia se consolidó bajo los preceptos del derecho privado, bien mediante la concepción de la responsabilidad indirecta, ora de la responsabilidad indirecta”. Diego Younes Moreno, Curso de Derecho Administrativo, 325 (10.a ed., Temis, 2016).

19 "Art. 1. De las expropiaciones, así como los daños en propiedad ajena, por órdenes o providencias administrativas nacionales, fuera del caso, previsto en el artículo 33 de la Constitución será responsable la nación cuando haya redundado en provecho suyo". Ley 30 de 1918. Por la cual se abre un crédito adicional al Presupuesto de gastos de la vigencia en curso. 15 de octubre de 1918. D. O. 16518. 
20 "La responsabilidad atribuida al Consejo de Estado por el Código Contencioso Administrativo de 1941 era por ello mismo de derecho público, pero al fin y al cabo excepcional”. Ramiro Saavedra Becerra, La responsabilidad patrimonial de la Administración Pública, 128-129 (Ibáñez, 2003).

21 "Art. 34. Conoce privativamente y en una sola instancia del Consejo de Estado de los siguientes negocios: 1. De las contenciones sobre suministros, empréstitos y expropiaciones en tiempo de guerra; 2. De las indemnizaciones a cargo del Estado por causa de trabajos públicos nacionales; [...]”. Ley 167 de 1941. Sobre organización de la jurisdicción Contencioso-administrativa. 24 de diciembre de 1941. D. O. 24853.

22 Consejo de Estado, 29 de julio de 1947, C.P. Gustavo Valbuena. Cursiva propia del texto original.

23 Consejo de Estado, 30 de septiembre de 1960, C.P. Francisco Gómez. En Anales del Consejo de Estado, Tomo 63, Bis, 1961, p. 778.

24 "Como ya se ha anotado, en la misma época en que la Corte Suprema tenía una competencia general en la materia, el Consejo de Estado tenía una competencia residual que sólo se torna general en 1964, lo cual implica que aun antes de 1964 el Consejo de Estado hizo sus aportes, y de suma importancia, para que se consolidara dicha responsabilidad en nuestra historia jurídica, que luego de 1964 ya es manejada exclusivamente por esta jurisdicción”. Juan Carlos Henao Pérez, Presentación general de la responsabilidad extracontractual del Estado en Colombia, en Segundas Jornadas colombovenezolanas, 754 (Editorial Universidad Externado de Colombia, 1996).

25 "Art. 30. La Sala de lo Contencioso Administrativo del Consejo de Estado, además de las funciones que le señalan la Ley 167 de 1941 y las que la adicionan y reforman, conoce: $1^{\circ}$ En única instancia: [...]. b)\# De las controversias sobre responsabilidad de la Administración Nacional o de los establecimientos públicos descentralizados del orden nacional, por sus actuaciones, omisiones, hechos, operaciones, y vías de hecho, cuando la cuantía sea o exceda de cien mil pesos; [...]. $2^{\circ} \#$ En segunda instancia, de todos los asuntos atribuidos en primera instancia a los Tribunales Administrativos. [...]”. “Art. 86. Acción de reparación directa. La persona interesada podrá demandar directamente la reparación del daño cuando la causa sea un hecho, una omisión, una operación administrativa o la ocupación temporal o permanente de inmueble por causa de trabajos públicos o por cualquiera otra causa. Las entidades públicas deberán promover la misma acción cuando resulten condenadas o hubieren conciliado por una actuación administrativa originada en culpa grave o dolo de un servidor o ex servidor público que no estuvo vinculado al proceso respectivo, o cuando resulten perjudicadas por la actuación de un particular o de otra entidad pública”. Decreto 01 de 1984 [con fuerza de ley]. Por el cual se reforma el Código Contencioso Administrativo. 2 de enero de 1984. D. O. 36439.

27 Consejo de Estado, 28 de abril de 1967, C.P. Carlos Portocarrero. En Anales del Consejo de Estado, Tomo 72, 1967, p. 275.

28 Consejo de Estado, 28 de octubre de 1976, C.P. Jorge Valencia.

29 Consejo de Estado. Exp. 3646, M. P. Jorge Valencia Arango; 9 de agosto de 1984.

30 Consejo de Estado. Exp. 5084, M. P. Carlos Betancur Jaramillo; 5 de julio de 1988.

31 Consejo de Estado. Exp. 5284, M.P. Carlos Betancur Jaramillo; 31 de enero de 1989.

32 Ley 1437 de 2011. Por la cual se expide el Código de Procedimiento Administrativo y de lo Contencioso Administrativo. 18 de enero de 2011. D. O. 47956.

33 Consejo de Estado, Sección Tercera, Exp. 29028, M.P. Ramiro Pazos Guerrero; 20 de febrero de 2014.

34 Consejo de Estado, Sentencia de 17 de agosto de 2017, Exp. 56347, C. P. Carlos Zambrano.

35 “(...) la Constitución Política de 1991 reconoció por primera vez en el país, de manera expresa, el principio general de la responsabilidad del Estado”. Ramiro Saavedra Becerra, op. cit., 142.

36 "Sin embargo, la consagración del Estado social de Derecho en la Constitución de 1991 amplió, sin duda, el espectro de la responsabilidad. Por una parte, a temas como los derechos humanos, por fuera de la lógica del derecho privado, y por otra, a todas las actividades de la administración incluso a la jurisdiccional y la legislativa, tradicionalmente excluidas [...]". Gustavo Quintero Navas, La construcción de la responsabilidad del Estado en Colombia, en Manual de Derecho Administrativo, 242 (Universidad de los Andes, 2009).

37 Enrique Gil Botero, Responsabilidad extracontractual del Estado, 20 (Editorial Temis, 2013).

38 "Es claro que cuando el inciso segundo del artículo 90 de la Constitución Política colombiana estableció que 'en el evento de ser condenado el Estado a la reparación de uno de tales daños (antijurídicos), que haya sido consecuencia de la conducta culposa o gravemente dolosa de un agente suyo, aquel repetirá contra este', consagró el deber de cobrar económicamente al agente, la reparación del daño causado por un tal obrar”. Juan Carlos Henao Pérez, Reflexiones sobre el futuro de la responsabilidad extracontractual del Estado en Colombia, en Congreso internacional de Derecho Público, Filosofía y Sociología Jurídicas: perspectivas para el próximo milenio, 736 (Universidad Externado de Colombia, Consejo Superior de la Judicatura, 1996).

39 "La acción de repetición es de naturaleza civil, de alcance subsidiario, con un marco operativo limitado por el ámbito de la responsabilidad patrimonial del Estado, pues ella supone que la condena ha tenido como causa necesaria la conducta dolosa o gravemente culposa del agente”. Jaime Vidal Perdomo, Derecho Administrativo, 497 (Legis, 2009). 
40 "La inclusión en la Constitución de daño antijurídico lo conduce a integrar de manera forzada un concepto que desconoce totalmente. Así, pues, en lugar de avanzar en la construcción jurisprudencial, el juez se enfrasca en una gran discusión sobre el alcance de la noción y mantiene como espectadores nerviosos a los demandantes. Todo esto explica los ires y venires de la jurisprudencia para finalmente mantenerse en el estado anterior al de la Constitución de 1991". Gustavo Quintero Navas, La responsabilidad del Estado en la Constitución de 1991: ¿Hacia el fin del fallo blanco?, en Corte Constitucional 10 años. Balance y perspectivas, 231 (Universidad del Rosario, 2003).

41 "En efecto, la norma simplemente establece dos requisitos para que opere la responsabilidad, a saber, que haya un daño antijurídico y que éste sea imputable a una acción u omisión de una autoridad pública. Pero el artículo 90 no restringe esta responsabilidad patrimonial al campo extracontractual, sino que consagra un régimen general, por lo cual la Corte no considera de recibo el argumento de uno de los intervinientes, según el cual la noción de daño antijurídico no es aplicable en el ámbito contractual". Corte Constitucional de Colombia. Sentencia C-333 de 1996 (M. P. Alejandro Martínez; 1 de agosto de 1996).

42 "Esta protección constitucional al patrimonio de los particulares se configura, entonces, cuando concurren tres presupuestos fácticos a saber: un daño antijurídico o lesión, una acción u omisión imputable al Estado y una relación de causalidad". Corte Constitucional de Colombia. Sentencia C-892 de 2001 (M. P. Rodrigo Escobar; 22 de agosto de 2001).

43 "Esta protección constitucional al patrimonio de los particulares se configura, entonces, cuando concurren tres presupuestos fácticos a saber: un daño antijurídico o lesión, una acción u omisión imputable al Estado y una relación de causalidad”. Corte Constitucional de Colombia. Sentencia C-644 de 2011 (M. P. Jorge Palacio; 31 de agosto de 2011).

44 "En suma, para la configuración de la responsabilidad patrimonial del Estado consagrada en el artículo 90 constitucional es necesaria la comprobación de (a) un daño antijurídico, (b) que le sea imputable al Estado (...) (causalidad jurídica), y que sea (c) producido por una acción u omisión de una entidad pública o de alguno de sus agentes (causalidad material)". Corte Constitucional de Colombia. Sentencia C-286 de 2017 (M. P. Gloria Ortíz; 3 de mayo de 2017).

45 "En el contexto de los procesos de reparación directa, la jurisprudencia del Consejo de Estado, en calidad de órgano de cierre de los litigios y controversias en lo contencioso administrativo, estableció los requisitos para que se configure esta clase de responsabilidad patrimonial, a saber: (i) la existencia de un daño antijurídico (...), (ii) que la acción u omisión desplegada sea imputable jurídicamente a las entidades públicas (...) y (iii) que se presente una relación de causalidad material entre el daño antijurídico y el órgano estatal (...). Así, el Estado responderá por los daños antijurídicos que le sean imputables jurídica y fácticamente”. Corte Constitucional de Colombia. Sentencia T-066 de 2019 (M. P. Alejandro Linares; 19 de febrero de 2019).

46 "El artículo consagrado a la reparación directa regula las pretensiones que pueden pedirse ante la jurisdicción de lo contencioso administrativo con el fin de obtener el restablecimiento de los derechos y la reparación de los daños originados por un hecho de las entidades públicas, entendiendo por tal aquel obrar que no puede ser calificado como un acto jurídico (acto administrativo unilateral o contrato estatal)”. Enrique José Arboleda Perdomo, Comentarios al Nuevo Código de Procedimiento Administrativo y de lo Contencioso Administrativo, 219 (Legis, 2011).

47 Consejo de Estado, Sección Tercera, Subsección A, Exp. 48964, M. P. Martha Velásquez; 16 de mayo de 2019.

48 Consejo de Estado, Sección Tercera, Subsección A, Exp. 43332, M. P. Adriana Marín; 8 de mayo de 2019.

49 Consejo de Estado, Sección Tercera, Subsección A, Exp. 36898, M. P. Carlos Zambrano; 17 de agosto de 2017.

50 Consejo de Estado, Sección Tercera, Subsección B, Exp. 39867, M. P. Martín Bermúdez;2 de agosto de 2019.

51 Consejo de Estado, Sección Tercera, Subsección B, Exp. 44900, M. P. Alberto Montaña; 15 de julio de 2019.

52 Consejo de Estado, Sección Tercera, Subsección B, Exp. 37646, M. P. Ramiro Pazos; 14 de junio de 2018.

53 Consejo de Estado, Sección Tercera, Subsección C, Exp. 43506, M. P. Nicolás Yepes Corrales; 31 de mayo de 2019.

54 Consejo de Estado, Sección Tercera, Subsección C, Exp. 44745, M. P. Jaime Rodríguez; 29 de abril de 2019.

55 Consejo de Estado, Sección Tercera, Subsección C, Exp. 51198, M. P. Guillermo Sánchez; 19 de diciembre de 2017.

\section{Licencia Creative Commons CC BY 4.0}

Cómo citar este artículo: Hugo Andrés Arenas Mendoza, ¿Los elementos de la responsabilidad extracontractual del Estado en Colombia son dos o tres?: a propósito de la relación de causalidad, 69 Vniversitas (2020). https://doi.org/10.11144/Javeriana.vj69.eree 